Supporting Information for:

\title{
Kinetics of 1,5 Hydrogen Migration in Alkyl Radical Reaction Class
}

Artur Ratkiewicz* and Barbara Bankiewicz

Chemistry Institute, University of Bialystok, Hurtowa 1 15-399 Bialystok, Poland

AUTHOR EMAIL ADDRESS: artrat@uwb.edu.pl 


\begin{tabular}{|c|c|c|c|c|c|c|c|c|c|c|c|c|c|c|c|c|c|}
\hline Temp, K & $\mathrm{R} 2$ & R3 & R4 & R5 & R6 & R7 & R8 & R9 & R10 & R11 & R12 & R13 & R14 & R15 & R16 & R17 & R18 \\
\hline 300 & 0.90 & 1.00 & 0.84 & 0.71 & 0.81 & 0.84 & 0.87 & 0.79 & 0.84 & 0.95 & 0.80 & 1.10 & 0.80 & 0.89 & 0.85 & 0.56 & 0.76 \\
\hline 400 & 0.83 & 0.93 & 0.84 & 0.80 & 0.83 & 0.90 & 0.82 & 0.84 & 0.78 & 0.83 & 0.77 & 0.97 & 0.84 & 0.82 & 0.85 & 0.77 & 0.83 \\
\hline 500 & 0.83 & 0.87 & 0.83 & 0.80 & 0.82 & 0.90 & 0.84 & 0.83 & 0.78 & 0.81 & 0.74 & 0.95 & 0.83 & 0.83 & 0.84 & 0.83 & 0.82 \\
\hline 600 & 0.83 & 0.83 & 0.82 & 0.80 & 0.81 & 0.90 & 0.83 & 0.83 & 0.78 & 0.81 & 0.74 & 0.94 & 0.82 & 0.82 & 0.84 & 0.83 & 0.82 \\
\hline 700 & 0.83 & 0.80 & 0.82 & 0.80 & 0.81 & 0.89 & 0.82 & 0.83 & 0.78 & 0.81 & 0.74 & 0.93 & 0.81 & 0.82 & 0.84 & 0.83 & 0.82 \\
\hline 800 & 0.83 & 0.79 & 0.82 & 0.80 & 0.80 & 0.88 & 0.81 & 0.83 & 0.78 & 0.82 & 0.75 & 0.93 & 0.80 & 0.82 & 0.84 & 0.83 & 0.82 \\
\hline 900 & 0.83 & 0.77 & 0.82 & 0.80 & 0.80 & 0.86 & 0.81 & 0.83 & 0.79 & 0.83 & 0.76 & 0.92 & 0.80 & 0.82 & 0.84 & 0.82 & 0.81 \\
\hline 1000 & 0.83 & 0.77 & 0.82 & 0.80 & 0.80 & 0.85 & 0.80 & 0.82 & 0.79 & 0.84 & 0.77 & 0.91 & 0.79 & 0.82 & 0.84 & 0.82 & 0.81 \\
\hline 1100 & 0.83 & 0.76 & 0.82 & 0.80 & 0.79 & 0.83 & 0.80 & 0.82 & 0.80 & 0.85 & 0.78 & 0.90 & 0.79 & 0.82 & 0.84 & 0.82 & 0.81 \\
\hline 1200 & 0.83 & 0.75 & 0.82 & 0.81 & 0.79 & 0.82 & 0.79 & 0.82 & 0.80 & 0.85 & 0.79 & 0.88 & 0.78 & 0.82 & 0.84 & 0.82 & 0.81 \\
\hline 1300 & 0.83 & 0.75 & 0.82 & 0.81 & 0.79 & 0.80 & 0.79 & 0.82 & 0.81 & 0.86 & 0.81 & 0.87 & 0.78 & 0.82 & 0.84 & 0.81 & 0.81 \\
\hline 1400 & 0.83 & 0.74 & 0.82 & 0.81 & 0.79 & 0.79 & 0.79 & 0.82 & 0.82 & 0.87 & 0.82 & 0.86 & 0.78 & 0.82 & 0.83 & 0.81 & 0.81 \\
\hline 1500 & 0.83 & 0.74 & 0.82 & 0.81 & 0.80 & 0.78 & 0.79 & 0.82 & 0.83 & 0.88 & 0.84 & 0.84 & 0.78 & 0.83 & 0.83 & 0.81 & 0.81 \\
\hline 1600 & 0.83 & 0.73 & 0.82 & 0.81 & 0.80 & 0.77 & 0.79 & 0.82 & 0.83 & 0.89 & 0.85 & 0.83 & 0.78 & 0.83 & 0.83 & 0.81 & 0.81 \\
\hline 1700 & 0.83 & 0.73 & 0.82 & 0.82 & 0.80 & 0.77 & 0.79 & 0.82 & 0.84 & 0.89 & 0.87 & 0.82 & 0.78 & 0.83 & 0.83 & 0.81 & 0.81 \\
\hline 1800 & 0.83 & 0.72 & 0.83 & 0.82 & 0.80 & 0.76 & 0.79 & 0.82 & 0.85 & 0.90 & 0.88 & 0.81 & 0.78 & 0.84 & 0.83 & 0.81 & 0.81 \\
\hline 1900 & 0.84 & 0.72 & 0.83 & 0.83 & 0.81 & 0.75 & 0.80 & 0.82 & 0.86 & 0.91 & 0.89 & 0.80 & 0.79 & 0.84 & 0.83 & 0.81 & 0.82 \\
\hline 2000 & 0.84 & 0.71 & 0.84 & 0.83 & 0.81 & 0.75 & 0.80 & 0.83 & 0.87 & 0.91 & 0.91 & 0.78 & 0.79 & 0.84 & 0.84 & 0.81 & 0.82 \\
\hline 2100 & 0.84 & 0.70 & 0.84 & 0.84 & 0.82 & 0.74 & 0.80 & 0.83 & 0.88 & 0.92 & 0.92 & 0.77 & 0.79 & 0.85 & 0.84 & 0.81 & 0.82 \\
\hline 2200 & 0.84 & 0.69 & 0.84 & 0.84 & 0.82 & 0.74 & 0.81 & 0.83 & 0.89 & 0.92 & 0.94 & 0.76 & 0.80 & 0.85 & 0.84 & 0.81 & 0.83 \\
\hline 2300 & 0.85 & 0.69 & 0.85 & 0.85 & 0.83 & 0.74 & 0.81 & 0.83 & 0.90 & 0.93 & 0.95 & 0.75 & 0.81 & 0.86 & 0.84 & 0.82 & 0.83 \\
\hline 2400 & 0.85 & 0.68 & 0.85 & 0.85 & 0.83 & 0.74 & 0.82 & 0.84 & 0.91 & 0.94 & 0.97 & 0.75 & 0.81 & 0.86 & 0.84 & 0.82 & 0.84 \\
\hline 2500 & 0.86 & 0.67 & 0.86 & 0.86 & 0.84 & 0.74 & 0.82 & 0.84 & 0.92 & 0.94 & 0.98 & 0.74 & 0.82 & 0.87 & 0.85 & 0.82 & 0.84 \\
\hline 2600 & 0.86 & 0.66 & 0.86 & 0.87 & 0.85 & 0.74 & 0.83 & 0.85 & 0.93 & 0.95 & 1.00 & 0.73 & 0.82 & 0.87 & 0.85 & 0.83 & 0.85 \\
\hline 2700 & 0.87 & 0.66 & 0.87 & 0.88 & 0.86 & 0.74 & 0.83 & 0.85 & 0.94 & 0.96 & 1.01 & 0.72 & 0.83 & 0.88 & 0.86 & 0.83 & 0.85 \\
\hline 2800 & 0.87 & 0.65 & 0.87 & 0.88 & 0.86 & 0.74 & 0.84 & 0.86 & 0.95 & 0.96 & 1.03 & 0.72 & 0.84 & 0.88 & 0.86 & 0.84 & 0.86 \\
\hline 2900 & 0.88 & 0.64 & 0.88 & 0.89 & 0.87 & 0.74 & 0.85 & 0.86 & 0.96 & 0.97 & 1.04 & 0.71 & 0.85 & 0.89 & 0.86 & 0.84 & 0.87 \\
\hline 3000 & 0.88 & 0.63 & 0.89 & 0.90 & 0.88 & 0.74 & 0.86 & 0.87 & 0.97 & 0.98 & 1.06 & 0.71 & 0.86 & 0.90 & 0.87 & 0.85 & 0.87 \\
\hline
\end{tabular}

Table S1. Hindered rotation factors ( $k_{H O} / k_{H R}$ values) for reactions R2-R18 from the training set. 


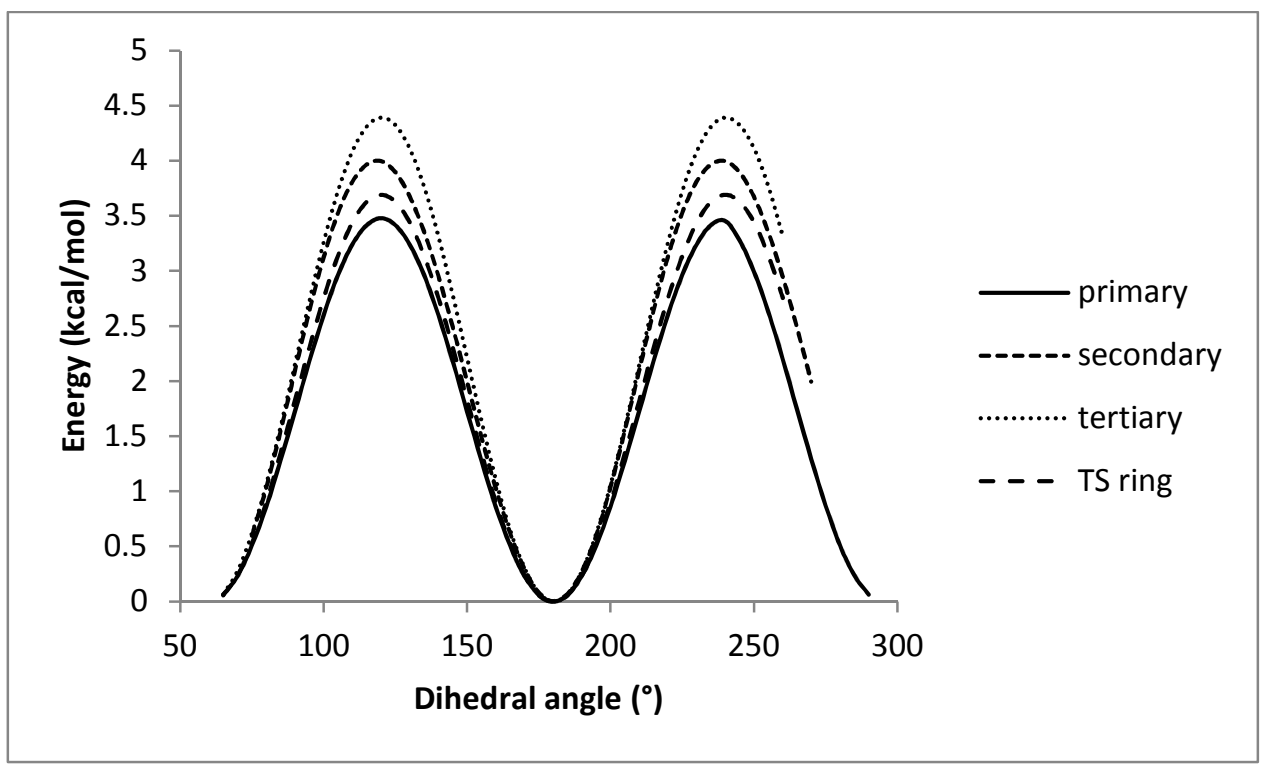

Figure S1. The potential curves for hindered internal rotation of a methyl groups connected to primary, secondary and tertiary carbon atoms in alkyl radicals and methyl group connected to the transition state ring of the 1,5 internal hydrogen migration. The potential is compiled as a relaxed scan with a resolution of $5^{\circ}$ at the BH\&HLYP/cc-pVDZ level of theory. 